\title{
Maternal and fetal factors associated with non detection of fetal growth restriction at term: a retrospective study
}

\author{
Atiya Aziz, Shyamji Tiwari, Madhusudan Dey, Suneeta Singh*
}

Department of Obstetrics and Gynecology, Base Hospital, Delhi Cantt., New Delhi, India

Received: 27 July 2020

Revised: 06 September 2020

Accepted: 08 September 2020

\author{
*Correspondence: \\ Dr. Suneeta Singh, \\ E-mail: suneetasingh01@gmail.com
}

Copyright: () the author(s), publisher and licensee Medip Academy. This is an open-access article distributed under the terms of the Creative Commons Attribution Non-Commercial License, which permits unrestricted non-commercial use, distribution, and reproduction in any medium, provided the original work is properly cited.

\begin{abstract}
Background: Fetal growth restriction (FGR) is one of the major factors of perinatal morbidity and mortality. Aim was to study the maternal and fetal risk factors associated with non- detection of fetal growth restriction.

Methods: A retrospective analysis was done at a tertiary care hospital. 280 term newborn cases weighing $<2.5 \mathrm{~kg}$ were selected and they were divided into two groups, Group I- FGR detected cases by ultrasound, and group II- FGR non detected cases. Data was collected from the labour room registers.

Results: Incidence of FGR found to be $6.8 \%$. The maternal biological factors found to be significantly associated with fetal growth restriction were gestational hypertension, chronic hypertension and anemia. Fewer ANC visits was associated with non-detection of FGR cases. Detection of FGR cases were more if the birth weight found to be $<2 \mathrm{~kg}$ when compared to non detection of FGR cases.

Conclusions: Anaemia and fewer ante natal visits were associated with non detection of FGR at term when compared with antenatally detected FGR patients.
\end{abstract}

Keywords: Anemia, Ante natal checkup, Birth weight, Fetal growth restriction, Term pregnancy

\section{INTRODUCTION}

Fetal growth restriction (FGR) is described as the inability of a fetus to reach its designated growth potential at any gestational age. ${ }^{1}$ The term FGR is often used synonymously with small for gestational age (SGA), defined as a birth weight (BW) or estimated fetal weight $(\mathrm{EFW})<10^{\text {th }}$ percentile for gestational age and sex. Fetuses identified as growth restricted are comprised of a heterogeneous group regarding etiological factors, management, and prognosis. ${ }^{2}$ Many fetuses or infants with birth weight $<10^{\text {th }}$ percentile are perfectly normal and simply "constitutionally" small. ${ }^{1}$

The overall incidence of FGR depends on the diagnostic criteria used, and the population being examined. It is estimated that between 3 to $9 \%$ of pregnancies in the developed world and up to $25 \%$ of pregnancies in low- middle income countries are affected by FGR. ${ }^{3}$ Fetal growth restriction is an important risk factor for perinatal morbidity and mortality. Advances in obstetric monitoring are more likely to detect placental insufficiency and fetal growth restriction during pregnancy. Umbilical artery Doppler examination is the most valuable tool regarding the prediction of perinatal outcome in growth-restricted fetuses ${ }^{1}$ and is accepted as the primary assessment tool regarding evaluation of FGR ${ }^{4}$ However, a significant proportion (up to $50 \%$ ) of FGR fetuses remain undiagnosed, and are first recognized only very late in pregnancy or at birth. ${ }^{5}$ An early antenatal detection, choosing the optimal time and method of delivery and treatment where appropriate could minimize the risks significantly. ${ }^{6,7}$

There are two major areas of conflict in managing FGR cases. First is the difficulty to distinguish between normal 
and and pathologically growth restricted fetus. Second is low antenatal detection rate of growth restricted fetus. The aim of this study was to identify the maternal and fetal factors associated with non detection of fetal growth restriction.

\section{METHODS}

A retrospective study was conducted at a tertiary care Hospital in Delhi, Base Hospital Delhi Cantt. over 2 years from 01 January 2018 to 31 December 2019. 280 patients who had delivered newborns with birth weight $\leq 2.5 \mathrm{~kg}$ at term (37 completed weeks of gestation and beyond) were selected for the study. They were divided into two groups- Group I, which were diagnosed as cases of fetal growth restriction (FGR) during antenatal period by ultrasound detection of fetal weight $<10^{\text {th }}$ percentile for corresponding gestational age and underwent delivery for this indication either by induction of labour, spontaneous delivery or caesarean section. The second group, Group II- includes, delivered newborns with birth weight $\leq 2.5 \mathrm{~kg}$ at 37 completed weeks or beyond but were not diagnosed as FGR during antenatal period and underwent spontaneous delivery or induction of labour for reasons other than FGR. $2.5 \mathrm{~kg}$ birth weight at 37 weeks of gestation or beyond considered FGR $\left(<10^{\text {th }}\right.$ percentile).

The main outcomes studied were the association of any co-morbidity in mothers and fetal growth restriction; we also studied about the adherence of regular ANC visits. Gestational hypertension has been defined according to the ACOG criteria. ${ }^{8}$ Gestational diabetes was defined according to the International Association of Diabetes and Pregnancy Study Groups Consensus Panel. ${ }^{9}$ First trimester maternal BMI were noted.

Patients were considered anaemic if haemoglobin level was $<10 \mathrm{gm} \%$ at the time of delivery. For socio-economic status, monthly income was taken into consideration and divided in three groups namely low (Rs $<30,000$ ), middle (Rs 30,000-60,000), and high (Rs $>60,000)$. The fetal outcomes in the form of mode of delivery, APGAR score, Birth weight, NICU admission, any anomalies and mortality were noted. APGAR score of 8 or less at 5 minutes was considered minor depression and score 6 or less at 5 minutes was considered severe depression. ${ }^{10}$ Local institutional ethical committee approved the study protocol.

\section{Statistical analysis}

Statistical analysis was carried out by using EPI 2007. For this study, analysis of socio-demographic factors, obstetric risk factors and outcomes were done by calculating the chi-squared test or Fisher's exact test for categorical variables and the Student's t-test for continuous variables. The $p$ values of less than 0.05 was considered as statistically significant.

\section{RESULTS}

The total number of births during this 2 year period was 5112 in the tertiary care hospital. A total number of 318 cases of fetal growth restricted newborns were delivered during this period. The incidence of FGR in our institution is $6.2 \%$. But 38 cases of FGR diagnosed by ultrasound were delivered before 37 completed weeks because of severe growth restriction, severe preeclampsia and they were not included in the study.

A total number of 280 patients were selected in the study. A total of 280 newborns had birth weight $\leq 2.5 \mathrm{~kg}$ at term were selected in the study as this was the criteria we choose for diagnosis of FGR and it is also considered as low birth weight as per Indian standard. As seen in Table 1 , the age distribution, pre-pregnancy weight, parity among both groups was similar.

Table 1: Maternal characteristics in FGR detected and FGR undetected and the total group.

\begin{tabular}{|lllll|}
\hline $\begin{array}{l}\text { Maternal } \\
\text { characteristics }\end{array}$ & $\begin{array}{l}\text { FGR detected group } \\
\text { Age }\end{array}$ & $\begin{array}{l}\text { FGR undetected } \\
\text { (Group II) } \mathbf{n = 1 0 3}\end{array}$ & Total $\mathbf{n = 2 8 0}$ & P value \\
\hline <30 years & $144(81.3 \%)$ & $89(86.4 \%)$ & $233(83.2 \%)$ & $>0.05$ \\
\hline$>\mathbf{3 0}$ years & $33(18.6 \%)$ & $14(13.6)$ & $47(16.8 \%)$ & $>0.05$ \\
\hline BMI & & & \\
\hline Normal & $154(87 \%)$ & $88(85.5 \%)$ & $242(86.4 \%)$ & $>0.05$ \\
\hline Overweight & $23(12.8 \%)$ & $13(11.6 \%)$ & $35(12.5 \%)$ & $>0.05$ \\
\hline Obese & $05(2.8 \%)$ & $02(2.6 \%)$ & $07(2.5 \%)$ & $>0.05$ \\
\hline Socioeconomic status & & & \\
\hline High & $15(8.5 \%)$ & $12(11 \%)$ & $27(9.6 \%)$ & $>0.05$ \\
\hline Middle & $152(87 \%)$ & $89(86.4 \%)$ & $241(86 \%)$ & $>0.05$ \\
\hline Low & $10(4.5 \%)$ & $02(2.6 \%)$ & $12(4.4 \%)$ & $>0.05$ \\
\hline Parity & & & $>0.05$ \\
\hline Nulliparous & $102(57.6 \%)$ & $67(65 \%)$ & $169(60.3 \%)$ & $>0.05$ \\
\hline Multipara & $75(42.4 \%)$ & $36(35 \%)$ & $111(39.7 \%)$ & \\
\hline
\end{tabular}




\begin{tabular}{|c|c|c|c|c|}
\hline $\begin{array}{l}\text { Maternal } \\
\text { characteristics }\end{array}$ & $\begin{array}{l}\text { FGR detected group } \\
\text { (Group I) } \mathbf{n = 1 7 7}\end{array}$ & $\begin{array}{l}\text { FGR undetected } \\
\text { (Group II) } \mathbf{n = 1 0 3}\end{array}$ & Total $n=280$ & $P$ value \\
\hline \multicolumn{5}{|c|}{ Number of pregnancies } \\
\hline$\leq 1$ & $76(43 \%)$ & $55(55.3 \%)$ & $131(46.7 \%)$ & $>0.05$ \\
\hline $2-3$ & $92(51.9 \%)$ & $45(42.8 \%)$ & $147(52.5 \%)$ & $>0.05$ \\
\hline$\geq 4$ & $9(5 \%)$ & $03(2.9 \%)$ & $12(4.2 \%)$ & $>0.05$ \\
\hline \multicolumn{5}{|c|}{ Hospitalisation during pregnancy } \\
\hline Yes & $13(7.3 \%)$ & $07(6.8 \%)$ & $20(7.4 \%)$ & $>0.05$ \\
\hline No & $164(92.7 \%)$ & $96(93.2 \%)$ & $260(92.6 \%)$ & $>0.05$ \\
\hline \multicolumn{5}{|l|}{ Comorbidity } \\
\hline PIH & $20(11.3 \%)$ & $02(1.9 \%)$ & $22(7.8 \%)$ & $<0.05$ \\
\hline Chr HTN & $04(2.2 \%)$ & $03(2.9 \%)$ & $07(2.5 \%)$ & $>0.05$ \\
\hline IVF & $07(4 \%)$ & Nil & $07(2.5 \%)$ & $>0.05$ \\
\hline IHCP & $10(5.6 \%)$ & $04(3.8 \%)$ & $14(5 \%)$ & $>0.05$ \\
\hline GDM & $10(5.6 \%)$ & $02(1.9 \%)$ & $12(4.3 \%)$ & $>0.05$ \\
\hline APLA & $05(2.8 \%)$ & Nil & $05(1.8 \%)$ & - \\
\hline Hypothyroidism & $05(2.8 \%)$ & $03(2.9 \%)$ & $08(2.8 \%)$ & $>0.05$ \\
\hline Anaemia & $11(6.2 \%)$ & $17(16.5 \%)$ & $28(10 \%)$ & $<0.05$ \\
\hline \multicolumn{5}{|l|}{ ANC visits } \\
\hline Unbooked & $04(2.2 \%)$ & $11(10.7 \%)$ & $15(5.4 \%)$ & $<0.05$ \\
\hline$<4$ visits & $11(6.2 \%)$ & $14(13.6 \%)$ & $25(9 \%)$ & $>0.05$ \\
\hline 5-7 visits & $29(16.4 \%)$ & $19(18.4 \%)$ & $48(17.1 \%)$ & $>0.05$ \\
\hline$>7$ visits & $133(75.2 \%)$ & $59(57.3 \%)$ & $192(68.5 \%)$ & $<0.05$ \\
\hline
\end{tabular}

Table 2: Fetal characteristics in FGR detected and FGR undetected and the total group.

\begin{tabular}{|c|c|c|c|c|}
\hline $\begin{array}{l}\text { Fetal characteristics } \\
\text { Birth weight }(\mathbf{k g})\end{array}$ & FGR detected (Group I ) n=177 & FGR undetected (Group II) n=103 & Total & $P$ value \\
\hline \multicolumn{5}{|l|}{ Birth weight (kg) } \\
\hline 2- 2.5 & $142(80.2 \%)$ & $98(95.1 \%)$ & $240(85.7 \%)$ & $>0.05$ \\
\hline 1.6-1.9 & $33(18.6 \%)$ & $05(4.9 \%)$ & $38(13.5 \%)$ & $<0.05$ \\
\hline 1.5 and less & $02(1.2 \%)$ & Nil & $02(0.8 \%)$ & - \\
\hline \multicolumn{5}{|l|}{ Fetal anomalies } \\
\hline Yes & $04(2.2 \%)$ & $02(1.9 \%)$ & $06(2.1 \%)$ & $>0.05$ \\
\hline No & $173(97.8 \%)$ & $101(97.9 \%)$ & $274(97.9 \%)$ & $>0.05$ \\
\hline \multicolumn{5}{|l|}{ APGAR score } \\
\hline Severe depression & $05(2.8 \%)$ & $02(1.9 \%)$ & $07(2.5 \%)$ & $>0.05$ \\
\hline Minor depression & $23(13 \%)$ & $07(6.8 \%)$ & $30(10.7 \%)$ & $>0.05$ \\
\hline Normal & $149(84.2 \%)$ & $94(91.3 \%)$ & $243(86.8 \%)$ & $>0.05$ \\
\hline \multicolumn{5}{|l|}{ NICU admission } \\
\hline Yes & $06(3.8 \%)$ & $02(1.9 \%)$ & $08(2.8 \%)$ & $>0.05$ \\
\hline No & $171(96.2 \%)$ & $101(97.9 \%)$ & $272(97.2 \%)$ & $>0.05$ \\
\hline \multicolumn{5}{|l|}{ Mode of Delivery } \\
\hline Normal Delivery & $104(58.7 \%)$ & $74(71.9 \%)$ & $178(63.5 \%)$ & $>0.05$ \\
\hline Caesarean & $70(39.5 \%)$ & $28(27.2 \%)$ & $98(35 \%)$ & \multirow{3}{*}{$<0.05$} \\
\hline Primary & 43 & 16 & 59 & \\
\hline Secondary & 27 & 12 & 39 & \\
\hline Instrumental & $03(1.8 \%)$ & $01(0.9 \%)$ & $04(1.4 \%)$ & $>0.05$ \\
\hline Perinatal mortality & $1(0.5 \%)$ & $1(0.9 \%)$ & $2(0.7 \%)$ & $>0.05$ \\
\hline
\end{tabular}

As noted in Table 1, $10.7 \%$ (n-11) were unbooked cases in group II (FGR undetected) as compared to $2.2 \%$ (n-4) in group I (FGR detected). The chances of not missing FGR is more among patients who have regular frequent ANC visits. In our study, (75.2\%), n-133 in group I had $>7$ visits as compared to $\mathrm{n}-59(57.3 \%)$ in group II.
The distribution of age group, parity and socio economic status was similar in both the groups. The incidence of co-morbidity (hypertension, diabetes, anti-phospholipid antibody syndrome, intra hepatic cholestasis of pregnancy, hypothyroidism, anemia) was $40.6 \%$ (n-72) in Group I as compared to $n-31(30 \%)$. Among these the 
incidence of hypertensive disease in pregnancy was statistically significant in group I with $\mathrm{p}$ value $<0.05$. More cases of anaemia were found in group II and this was also found to be statistically significant. 05 foetuses in group I had increased umbilical artery Doppler systolic/diastolic (S/D) ratio. All the foetuses with absent or reversed umbilical artery diastolic flows were delivered before 37 completed weeks.

Among the fetal factors, newborns with birth weight $>2$ $\mathrm{kg}$ were 142 (80.2\%) in group I as compared to 98 (95\%) in group II, and the newborns with birth weight of 1.6-1.9 $\mathrm{kg}$ were $33(18.6 \%)$ in group I as compared to $05(5 \%)$ in group II and this was statistically significant. This shows that the incidence of detecting FGR is more if birth weight is $<2 \mathrm{~kg}$.

The incidence of NICU admission was 3.8\% (n-6) and $1.9 \%$ (n-2) in group I and II respectively, but it was not statistically significant. The incidence of caesarean section was $39.5 \%(\mathrm{n}-70)$ and $27.2 \%(\mathrm{n}-28)$ among Group I and II respectively, this was statistically significant $\mathrm{p}<0.05$. The incidence of fetal distress was more in group I, but it was not statistically significant.

There were one perinatal mortality in each group. Both the fetus had birth weight of $1.65 \mathrm{~kg}$ and $1.7 \mathrm{~kg}$ respectively. They were born with severe depression and were on ventilator for 3 days.

\section{DISCUSSION}

A recent population based study confirmed that FGR is the single largest risk factor for stillbirth, increasing the stillbirth rate four fold compared to pregnancies with normally grown foetuses. Antenatal non-detection further increases the stillbirth rate by a factor of two. ${ }^{11}$ An early antenatal detection, treatment where appropriate and choosing the optimal time and method of delivery could minimize the risks significantly. ${ }^{6,7}$ A significant proportion (up to 50\%) of FGR fetuses remain undiagnosed, and are first recognized only very late in pregnancy or at birth. ${ }^{5}$ Till now low antenatal detection rates of suboptimal fetal growth through routine fetal ultrasonography have been reported. ${ }^{12}$

Finding out of maternal and fetal factors associated with non detection of FGR cases would help the clinicians to be more vigilant during antenatal care and to avoid missing FGR cases. In our study FGR was diagnosed in $63.2 \%$ ( $n-177$ of the total 280 cases) during antenatal period. This rate of detection is more than seen in other studies where the detection rate was about $50 \% .{ }^{5}$ Chances of not missing FGR cases was more in neonates with birth weight of $<2 \mathrm{~kg}$ as seen in the study by Alexandra et al. ${ }^{13}$ This can be picked up by diligent obstetric examination and third trimester ultrasound and fetal Doppler studies if indicated. The present study also confirms that most of the cases of FGR missed if the birth weight is between $2-2.5 \mathrm{~kg}$ as $95 \%$ of non-detected FGR cases were falling in this group.

The association of hypertensive disorder in pregnancy and FGR was significant in our study, which has been also shown in numerous studies and $14 \%$ patients had hypertension related disorders in FGR detected group. ${ }^{14}$ This reiterates that during antenatal check-up one has to be very vigilant to avoid missing hypertension and its associated maternal and fetal complications.

The association of anemia with FGR was also significant in this study. Anemia is a common problem in developing countries and it increases the risk of low birth weight and FGR. ${ }^{15}$ It is an easily detectable and treatable problem. Women of reproductive age group who are planning to conceive should get their haemoglobin checked and take iron supplements if they are anaemic and all pregnant women should be encouraged to take iron supplements. Low socioeconomic status and low educational status leads to low health consciousness, lower nutritional status and low antenatal attendance, leading to the increased risk of FGR babies. ${ }^{16}$ In our study most of the patients were of middle socio-economic status and their nutritional status was good.

Most of the patients in group II who were diagnosed to have anaemia were unbooked cases as there was no time to build their haemoglobin level. As our centre is a tertiary care centre, we receive lot of obstetric cases in the last weeks of pregnancy who are not booked with us. It was seen in the study that the chances of non detection of FGR was more in the group who were unbooked and who had $<4$ visits at our centre. Regular ANC visit is of utmost importance to avoid missing FGR cases as it can be seen in present study that 7 or more ANC visits were associated with more detection of FGR. More visits were encouraged after detection of FGR for regular evaluation before admission and delivery. Thus the clientele has to be educated about the importance of regular antenatal checkups and to follow the advice given by the doctors.

Expectant management or early delivery is always a debatable issue in management of FGR cases. FGR diagnosed below 32 weeks of gestation were considered early onset FGR. ${ }^{17}$ Most of the early FGR is associated with preeclampsia and severe angiogenic disbalance as compared to late onset FGR. Several guidelines recommend delivery at 37-38 weeks. This recommendation is based on the findings of the DIGITAT study, in which 650 women with SGA > 36 weeks were randomized to induction or expectant management. Induction group infants were delivered 10 days earlier and weighed $130 \mathrm{gm}$ less than babies in the expectant monitoring group. There was no difference in the perinatal outcomes except that women in the expectant group had 2-fold increase in risk of developing preeclampsia. ${ }^{18}$ 
As it was a retrospective study, we didn't have the data of the ultrasound monitoring of the patients. The weight gain during pregnancy which can be a marker to pick up FGR is also lacking in our study.

\section{CONCLUSION}

FGR, a major contributor of perinatal morbidity and mortality is still being missed. Timely detection and delivery can result in better outcome. FGR is associated with maternal co-morbidities and other pregnancy related complication which develop as the pregnancy advances. Detailed regular antenatal checkups are a key to detect FGR cases and evaluate them further.

Funding: No funding sources Conflict of interest: None declared

Ethical approval: The study was approved by the Institutional Ethics Committee

\section{REFERENCES}

1. Creasy R, Resnik R. Intrauterine growth restriction. In: Resnik R, Creasy R, Iams J, Lockwood C, Moore T, Greene M, eds. Creasy and Resnik's MaternalFetal Medicine: Principles and Practice. 7th edn. Elsevier Health Sciences. Philadelphia: Pa, USA; 2014:743-755.

2. Sheridan C. Intrauterine growth restriction: diagnosis and management. Aust Fam Phys. 2005;34(9):71723.

3. Suhag A, Berghella V. Intrauterine growth restriction (IUGR): etiology and diagnosis. Curr Obstet Gynecol Rep. 2013;2:102-11.

4. Berkley E, Chauhan SP, Abuhamad A, Society for Maternal-Fetal Medicine Publications Committee. Doppler assessment of the fetus with intrauterine growth restriction. Am $\mathbf{J}$ Obstet Gynecol. 2012;206(4):300-8.

5. Lappen JR, Myers SA. The systematic error in the estimation of fetal weight and the underestimation of fetal growth restriction. Am J Obstet Gynecol. 2017;216:477-83.

6. Gardosi J, Madurasinghe V, Williams M, Malik A, Francis A. Maternal and fetal risk factors for stillbirth: population based study. BMJ. 2013;346.

7. Salam RA, Das JK, Bhutta ZA. Impact of intrauterine growth restriction on long-term health. Curr Opin Clin Nutr Metab Care. 2014;17(3):249-54.

8. ACOG practice bulletin no. 202: gestational hypertension and preeclampsia. Obstet Gynecol. 2019;133:e1-25.
9. International Association of Diabetes and Pregnancy Study Groups consensus panel (IADPSG) International Association of Diabetes and Pregnancy Study Groups recommendations on the diagnosis and classification of hyperglycaemia in pregnancy. Diabetes Care. 2010;33(3):676-82.

10. Papile LA. The Apgar score in $21^{\text {st }}$ century. $\mathrm{N}$ Engl $\mathrm{J}$ Med. 2001;344:519-20.

11. Alfirevic Z, Stampalija T, Gyte GML. Fetal and umbilical Doppler ultrasound in high-risk pregnancies. Cochrane Database Systemat Rev. 2013;11:CD007529.

12. Bricker L, Neilson JP, Dowswell T. Routine ultrasound in late pregnancy (after 24 weeks' gestation). Cochrane Database Systemat Rev. 2005;6:1154-8.

13. Ernst SA, Brand T, Reeske A, Spallek J, Petersen K, Zeeb H. Care-related and maternal risk factors associated with the antenatal nondetection of intrauterine growth restriction: a case-control study from Bremen, Germany. BioMed Res Int. 2017;2017.

14. Braunthal S, Brateanu A. Hypertension in pregnancy: pathophysiology and treatment. SAGE Open Med. 2019;7:2050312119843700.

15. Acharya D, Nagraj K, Nair NS, Bhat HV. Maternal determinants of intrauterine growth retardation: a case control study in Udupi District, Karnataka. Indian J Community Med. 2004;29(4):181-2.

16. Ferraz EM, Gray RH, Cunha TM. Determinants of preterm delivery and intrauterine growth retardation in north-east Brazil. Int $J$ Epidemiol. 1990;19(1):101-8.

17. Figueras F, Caradeux J, Crispi F, Eixarch E, Peguero A, Gratacos E. Diagnosis and surveillance of lateonset fetal growth restriction. Am J Obstet Gynecol. 2018;218(2):S790-802.

18. Boers KE, Vijgen SM, Bijlenga D, Van Der Post JA, Bekedam DJ, Kwee A, et al. Induction versus expectant monitoring for intrauterine growth restriction at term: randomised equivalence trial (DIGITAT). BMJ. 2010;341:c7087.

Cite this article as: Aziz A, Tiwari S, Dey M, Singh S. Maternal and fetal factors associated with non detection of fetal growth restriction at term: a retrospective study. Int J Reprod Contracept Obstet Gynecol 2020;9:4164-8. 